\title{
Chromatographic Quantitation of Some Bioactive Minor Components in Oils of Wheat Germ and Grape Seeds Produced as By-Products
}

\author{
Minar Mahmoud M. Hassanein* and Adel Gabr Abedel-Razek \\ National Research Centre, Fats and Oils Dept. (33 Tahrir St., Dokki, Cairo, EGYPT)
}

\begin{abstract}
The objective of this work was to determine some beneficial and bioactive minor lipid components in wheat germ and grape seeds as a result of milling industry of wheat and pressing of grapes in wineries. Sterylglycosides (SG's) were isolated and fractionate into free and acylated SG's by TLC and were determine as their1-anthroylnitriles (1-AN) by HPLC. Moreover, 4-desmethylsterols were isolated, derivatized into their trimethyl silyl derivatives and analyzed by GLC. Tocopherols and tocotrienols were directly analyzed by HPLC. In addition, fatty acids composition by GLC was accomplished. The results were compared to three conventional edible oils, namely, corn, sunflower and cottonseed. It was found that the wheat germ oil (WGO) and grape seed oil (GSO) contained reasonable amounts of whole sterols. Sterylglycosides fraction (SG), which have not been evaluated, it was found that the two by-products contained high amounts of SG's and they were rich in free and acylated campe/stigma SG as well as free and acylated $\beta$-sito SG. Total tocopherols and tocotrienols components were found in very high amounts in WGO $(1300 \mathrm{ppm})$ and GSO $(380 \mathrm{ppm})$. It is noteworthy to mention that GSO contained significant amounts of alpha- and gamma-tocotrienols which prevent cardiovascular diseases and contained reasonable amounts of alpha- and gamma-tocopherols. On the other side, it was found that WG and GS oils were enrich in linoleic acid (omega-6), while linolenic acid (omega-3) was present in higher quantity in WGO.
\end{abstract}

Key words: by-products, sterylglycosides, vitamin E, wheat germ oil, grape seed oil, omega-fatty acids

\section{INTRODUCTION}

The potential and current sources of oils, not only restricted to seeds, but also are included in food industry by-products. These by-products are obtained in tonnages such as grape pressing product obtained from the wineries and wheat germ produced from milling industry. It is well known that oils obtained from these by-products can be used for pharmaceutical and nutritional purposes ${ }^{1}$. The increase in production volume of these by-products resulted in an exponentional increase of these by-products in wheat milling and grape pressing industries. These byproducts contain some valuable substances such as fatty acids, tocopherols, sterols and sterylglycosides with potential applications in food industry mostly go to waste.

Subsequently, it was reported that WG constitute about $2-3 \%$ of the whole wheat kernel; it has an average moisture content of $14 \%$ and contains about $10 \%$ oil $^{2}$. The well known beneficial effect of WGO is basically due to their high content of vitamin $\mathrm{E}$ and unsaturated FA's, mainly linoleic $\mathrm{acid}^{3-7)}$. WGO has been found to reduce plasma and liver cholesterol in animals and to delay aging ${ }^{8,9}$. Nevertheless, because of its unfavorable baking properties and susceptibility to oxidation, the germ is removed from the endosperm during milling and is mainly used for fodder and for oil production ${ }^{10)}$. On the other side, WGO is obtained either by solvent extraction, which recovers about $90 \%$ of the oil, or by mechanical pressing which recovers about $50 \%{ }^{11)}$. The extracted WG oils usually need to be refined, owing to their high FFA content varying from 5 up to 25\%, depending on the conditions of milling, germ storage, and oil extraction ${ }^{12)}$. Additionally, supercritical $\mathrm{CO}_{2}$ was employed in extracting $\mathrm{WGO}^{13)}$. Phytosterols esters content were evaluated in the WGO and the phytosterols were enriched in the raffinate fraction ${ }^{7,14}$. Moreover,

* Correspondence to: Minar Mahmoud M. Hassanein, National Research Centre, Fats and Oils Dept., 33 Tahrir St., Dokki, Cairo, EGYPT E-mail: minarmahmoud@yahoo.com

Accepted January 8, 2009 (received for review November 4, 2008)

Journal of Oleo Science ISSN 1345-8957 print / ISSN 1347-3352 online

http://www.jstage.jst.go.jp/browse/jos/ 
they found that alpha-, beta-, and gamma-tocopherol in crude wheat oil amount to $13.9,1.1$ and $0.08 \mathrm{mg} / \mathrm{g}$ oil respectively. Barnes J.P. found that WGO exhibits a range of sterols ${ }^{6}$. 4-Methylsterols, $\beta$-sitosterol and campesterol are the major components. Barnes and Taylor in their study dealt with the composition of acyl lipids and tocopherols in WGO's from various sources ${ }^{15)}$.

On the other side, grape pressing in wineries resulted in huge amounts of grape pomace containing grape seeds that are used as a source of oil having nutritional and pharmaceutical implications. The oil has a clear, light taste that has been described as "nutty" and is safe for cooking food compared with other oils ${ }^{16)}$. In addition, GSO, a high linoleic acid (76.0\%) product, is the only food known to raise HDL (good cholesterol) and lower LDL (bad cholesterol). Linoleic acid (omega-6) is one of two essential fatty acids which can not be synthesized in the body and it is the precursor of a family of other fatty acids such as arachidonic acid and gamma-linolenic acid ${ }^{16,17)}$. Beveridge et al.,used two extraction methods; found that GSO is ranged from 5.85 to $13.6 \%$ and 6.64 to $11.17 \%$ with supercritical $\mathrm{CO}_{2}$ and petroleum ether extraction respectively ${ }^{18}$. Grape seed and pomace oils had nearly similar FA profile with higher linoleic acid and very low linolenic acid content that make the oil more resistant to autoxidation. Also oleic acid in grape seed and pomace oils has a great importance in terms of their nutritional implication and the effect on oxidation stability of the oil ${ }^{19-21}$. EL Mallah et al. studied the fatty cid, triacylglycerol, tocopherol, tocotrienol and whole sterol pattern of red grape, lettuce and soybean oil ${ }^{22}$. They found that the alpha and gamma-tocotrienols amount to 54.0 and $26.0 \%$ in red grape pomace. Additionally, it was reported that the enzymatic hydrolysis prior to cold pressing had a great influence on the yield of oil ${ }^{23)}$.

The objective of this work was to update the data of some bioactive and nutritional minor components of WG and GS oils, obtained from samples of freshly produced byproducts resulting from wheat milling and grape pressing industries. These components comprise tocopherols, tocotrienols, and whole sterols as well as free and acylated sterylglycosides beside fatty acids profile of the oils. UVHPLC and fluorescence-HPLC as well as capillary GLC were used for quantitative evaluation of these components. Tocopherols and tocotrienols in oils were determined by direct method, whereas sterols evaluated as TMS derivatives. In addition, sterylglycosides, as 1-anthroylnitrile derivatives whereas fatty acids were evaluated as their methyl esters. It is worthy to mention that the bioactive sterylglycosides, as far as one knows, have not been hitherto investigated particularly in local WG and G S oils. For comparison, compositions of traditional oils such as corn, sunflower and cottonseed oils are also determined. In general, the compositional data of WG and GS oils can provide additional updated information to those customers who are concerned with health and nutritional aspects for prevention of certain diseases.

\section{EXPERIMENTAL}

\subsection{Materials}

Freshly milled wheat germ sample was supplied by the Milling Organization, North Cairo, as by-product of wheat milling process (season 2006).

Grape pomace, by-product, containing grape seeds, of grape pressing (season 2006) was obtained from the Egyptian Vineyard and Distilleries Company (Ginaclis, Alexandria season 2006). Grape seeds, sieved out, from the air dried pomace and wheat germ were ground and subsequently extracted with chloroform/methanol $(2: 1, \mathrm{v} / \mathrm{v})$.

For comparison, seed oils, namely, corn, sunflower and cottonseed were extracted in the laboratory using the previous methods of analysis.

\subsection{Methods}

\subsubsection{Oil content}

The oil content was calculated on dry basis for wheat germ, grape seed, corn, sunflower and cottonseeds according to Official and Tentative Methods of the AOCS ${ }^{24)}$.

2.2.2 Fatty acids pattern

The oil was converted into methyl esters via transesterification with $5 \%$ hydrogen chloride gas in methanol ${ }^{17}$. Transesterification reaction was monitored with the help of TLC using silica gel G plates and n-hexane : diethyl ether : acetic acid (80:20:1,v/v/v) was used as a developing solvent Hewlett Packard-HP 5980-A gas chromatograph was employed for the analysis of the mixed methyl esters under the following operating conditions: column, DB-23 $(0.32 \mathrm{~mm} \times 30 \mathrm{~m})$; temperature programming, $150-230^{\circ} \mathrm{C}$, $3^{\circ} \mathrm{C} / \mathrm{min}$; injector, $230^{\circ} \mathrm{C}$; detector, FID at $240^{\circ} \mathrm{C}$; carrier gas, helium at flow rate of $1.3 \mathrm{~mL} / \mathrm{min}$ and split ratio, 100:1.Calibration was made using standard fatty acid methyl esters and the results were recorded by an electronic integrator as peak area percent with the help of standard chromatogram representing the following esters (14:0, 16:16:1,18:0,18:1,18:2,18:3,20:0 and 20:1).

2.2.3 Tocopherols and tocotrienols pattern (direct method)

HPLC analysis of tocopherols (T) and tocotrienols (T3), in the oil samples as well as the standard tocopherols mixture were carried out using Toyo-Soda-CCPM HPLC instrument. An oil sample (10 g) was dissolved in n-hexane to make $10 \%$ solution and $10 \mu \mathrm{L}$ was injected into silica column (YMC-A-012, 6.0 × $150 \mathrm{~mm}$ ). Isocratic elution was conducted using n-hexane: isopropyl alcohol (100:0.5, by volume) as mobile phase, at a flow rate of $1-2 \mathrm{~mL} / \mathrm{min}$. Hitachi650-10S fluorescence detector was used. Spectral absorption was set at excitation and emission wavelengths of 295 and $325 \mathrm{~nm}$ respectively. The conditions were optimized to 
elute delta-T after $10 \mathrm{~min}$, the results were automatically recorded as peak area percentages by electronic integrator. The HPLC pattern of the standard tocopherol and tocotrienol designated as $\alpha$-T, $\beta$-T, $\delta$-T, $\gamma$-T, $\alpha$-T3, $\beta$-T3, $\delta$ T3 and $\gamma$ T3. From the peak area and the corresponding weight of each individual standard $\mathrm{T}$ and $\mathrm{T} 3$, the weight of each individual $\mathrm{T}$ and $\mathrm{T} 3$ in the oil (ppm) can be calculat$\mathrm{ed}^{25,26)}$

\subsubsection{Whole sterols profile}

Whole sterols were isolated from the prepared unsaponifiable fractions of the oils by preparative TLC on silica gel $\mathrm{G}$ plates ( $0.5 \mathrm{~mm}$ thickness) using chloroform/ diethyl ether/ acetic acid (95/4/1 by volume) as a developing solvent ${ }^{24}$. The sterol zone was located with the help of standard beta-sitosterol $\left(\mathrm{R}_{\mathrm{f}}=0.16\right)$ applied alongside the sample prior to development. The scraped zone was thoroughly extracted with moistened diethyl ether, the solvent was distilled off and the prepared sterols mixtures were converted into trimethylsilyl derivatives (TMS) ${ }^{17)}$. The sterol composition of the oils were determined by the help of the standard chromatogram of cholesterol, brassica, 5stigma, B-sito, spina, isofuco, 7-stigma, avenasterol.

Hewlett Packard-HP 5890-A gas chromatograph, was employed for analysis using the following operating conditions: column, DB-17 ( $0.32 \mathrm{~mm} \times 15 \mathrm{~m}, 0.25 \mu \mathrm{m}$ coating) at $250^{\circ} \mathrm{C}$; detector, FID at $260^{\circ} \mathrm{C}$; carrier gas, helium $(8.6$ $\mathrm{mL} / \mathrm{min}$ ) and split ratio, 35:1. An automatic integrator was coupled directly to the detector. TMS sterols mixture of cotton seed oil (containing known percentages of sterols) was used for identification and quantification of the sterols in each oil sample. The area under each peak was measured by the automatic integrator ${ }^{27)}$.

2.2.5 Sterylglycosides profiles of free and acylated sterols

The procedure of separation of the sterylglycosides from the oil, derivatization into sterylglycosides 1-anthroylnitrile (SG-1-AN) and HPLC analysis were carried out according to Murui et al., and El-Mallah, et al. ${ }^{27,28)}$. The free sterylglycosides (FSG) and acylated sterylglycosides (ASG) were separated from the oil by injecting the oil solution into silica gel cartridge (sep-Pak,Waters) followed by elution with chloroform: methanol $(1: 1 \mathrm{v} / \mathrm{v})$. The eluate is the mixed sterylglycosides which were subsequently fractionated into pure FSG $\left(\mathrm{R}_{\mathrm{f}}=0.30\right)$ and $\mathrm{ASG}\left(\mathrm{R}_{\mathrm{f}}=0.61\right)$ with the help of preparative TLC. Chloroform/methanol/formic acid mixture (90/15/1, v/vv) was used as a developing solvent. Only ASG fraction was subjected to alkaline hydrolysis (0.5 N KOH in isopropyl alcohol) to obtain FSG. The original and obtained FSG after deacylation of ASG were derivatized separately, into SG-1-AN according to the same methods mentioned above. Standard FSG and ASG were kindly obtained from Dr. Tateo Murui of Nisshin Oil Mills Yokohama, Japan.

HPLC instrument, equipped with UV detector (Toso,UV $8000)$ and column, ODS Wakosil-5, $\mathrm{C}_{18}(6.4 \mathrm{~mm} \times 250 \mathrm{~mm})$ was used for SG-1-AN analysis. Gradient elution with acetonitrile/dichloromethane (from 50/50 to $68 / 32 \mathrm{v} / \mathrm{v}$ ) was used and absorption was measured at $254 \mathrm{~nm}$. It is noteworthy to mention that this method is sensitive to 0.5 nanogram of SG. The identification of the peaks was designated with the help of standard chromatogram as a guide for identification.

All the data are the mean of two concordant replicates and the difference did not exceed more than 0.2-0.4.

\section{RESULTS}

\subsection{Oil content}

The oil contents of wheat germ, grape seed ,corn, sunflower and cottonseeds were 11.0, 12.0, 15.0,19.6 and 22.6\% respectively Table 1.

\subsection{Fatty acids pattern}

Concerning the fatty acid patterns (Table 1) of wheat germ (WG) and grape seed (GS) oils, it was found that these oils contained appreciable amounts of linoleic acid (omega-6) i.e. 56.5 and $67.8 \%$ respectively in comparison to the three edible conventional oils, namely, corn, sunflower and cottonseed. In addition, WGO contained a reasonable amount (8.0\%) of linolenic acid (omega-3), whereas GS con-

Table 1 Fatty Acids Composition of Various Oil Samples by GLC.

\begin{tabular}{|l|c|c|c|c|c|c|c|}
\hline \multirow{2}{*}{ Oil Sample } & \multirow{2}{*}{$\begin{array}{c}\text { Oil Content } \\
\%\end{array}$} & $\begin{array}{c}\text { Palmitic } \\
(16: 0)\end{array}$ & $\begin{array}{c}\text { Stearic } \\
(18: 0)\end{array}$ & $\begin{array}{c}\text { Oleic } \\
(18: 1)\end{array}$ & $\begin{array}{c}\text { Linoleic } \\
(18: 2)\end{array}$ & $\begin{array}{c}\text { Linolenic } \\
(18: 3)\end{array}$ & $\begin{array}{c}\text { Unsaturation } \\
\%\end{array}$ \\
\hline Wheat germ & 11.0 & 20.0 & 1.0 & 14.7 & 56.5 & 8.0 & 79.0 \\
\hline Grape seed & 12.0 & 8.0 & 3.8 & 20.2 & 67.8 & 0.2 & 88.2 \\
\hline Corn & 15.0 & 8.3 & 4.4 & 42.0 & 45.1 & 0.2 & 87.3 \\
\hline Sunflower & 19.6 & 6.3 & 2.5 & 46.3 & 44.9 & - & 91.2 \\
\hline Cottonseed & 22.6 & 25.1 & 4.0 & 20.3 & 50.6 & - & 70.9 \\
\hline
\end{tabular}


tained a minor amount of this fatty acid (0.2\%). The monounsaturated fatty acid (oleic) is incorporated in the glycerides at $14.7 \%$ for WGO and $20.2 \%$ for the oil extracted from GS however, this acid constituted $42.0 \%$ in corn oil, $46.3 \%$ in sunflower oil and $20.3 \%$ in cottonseed oil. In WGO plamitic acid was the major component of the saturated fatty acids and amounted $20.0 \%$, whereas it constituted $8.0 \%$ of the fatty acids of GSO. In comparison with corn, sunflower and cottonseed oils, the latter contained higher amount of this acid (25.1\%), while corn and sunflower contained 8.3 and $6.3 \%$ respectively.

\subsection{Tocopherols and tocotrienols pattern}

It is known that vitamin $\mathrm{E}$ consists of eight different compounds, four tocopherols and four tocotrienols (designated as alpha-, beta-, gamma- and delta) ${ }^{29}$. Individual and total amounts of vitamin $\mathrm{E}$ (tocopherols and tocotrienols) contents of WG and GS oils compared with the three edible oils (corn, sunflower and cottonseed) are presented in Table 2).

Thus the total amount of vitamin E in WGO amounting $1300 \mathrm{ppm}$ which was markedly high, while in GSO reached $380 \mathrm{ppm}$ in comparison with 1017, 670 and $620 \mathrm{ppm}$ for corn, sunflower and cottonseed oils respectively. The individual components of vitamin $\mathrm{E}$ in $\mathrm{WGO}$ were $70.0,19.0$ and, $7.0 \%$ for alpha-, beta- and gamma-tocopherols respectively and $2.0 \%$ for both alpha- and gamma-tocotrienols. While GSO contained 10.0\% alpha-tocopherol, 2.5\% gamma-tocopherol, 37.5\% alpha-tocotrienol and 50.0\% gamma-tocotrienols. In comparison corn oil contained gamma-tocopherol as abundant component $(81.0 \%)$ while it exhibited lower amount of alpha-tocopherol (16.2\%) and a very low concentration of delta-tocopherol (2.0\%). On the contrary, sunflower oil possessed the predominating alphatocopherol which reached $96.0 \%$ of the total tocopherols however; it contained minor quantities of beta- and gamma-tocopherols. On the other side, cottonseed oil contained $43.5 \%$ alpha-tocopherol and $56.5 \%$ gamma-tocopherol.

\subsection{Pattern of whole sterols}

Prior to analysis, pure sterols mixtures were isolated from the unsaponifiable fractions via TLC of the oils and subsequently converted into silyl ethers derivatives. From the results in Table 3, it is clear that the sterols patterns of WG and GS oils included, campe , 5 -stigma, beta-sito, iso-

Table 2 Tocopherols and Tocotrienols Pattern of Various Oil Samples by HPLC.

\begin{tabular}{|c|c|c|c|c|c|c|c|}
\hline \multirow{2}{*}{ Oil Sample } & \multirow{2}{*}{$\begin{array}{l}\text { Tocopherol Total } \\
\text { (ppm) }\end{array}$} & \multicolumn{6}{|c|}{ Tocopherols and tocotrienols composition (\%) } \\
\hline & & $\alpha$-Toc. & $\beta$-Toc. & $\gamma$-Toc & $\delta$-Toc. & $\alpha-\mathrm{T} 3$ & $\gamma-\mathrm{T} 3$ \\
\hline Wheat germ & 1300 & 70.0 & 19.0 & 7.0 & - & 2.0 & 2.0 \\
\hline Grape seed & 380 & 10.0 & - & 2.5 & - & 37.5 & 50.0 \\
\hline Corn & 1017 & 16.2 & 0.8 & 81.0 & 2.0 & - & 2.0 \\
\hline Sunflower & 670 & 96.0 & 3.0 & 1.0 & - & - & - \\
\hline Cottonseed & 620 & 43.5 & - & 56.5 & - & - & - \\
\hline
\end{tabular}

Toc. : Tocopherol; $\alpha$-Toc. : Alpha-tocopherol ; $\beta$-Toc. : Beta- tocopherol ; $\gamma$-Toc. : Gamma-tocopherol ; $\delta$-Toc. : Delta-tocopherol ; T3 : Tocotrienol ; $\alpha$-T3 : Alpha-tocotrienol ; $\gamma$ - T3 : Gamma-tocotrienol.

Table 3 Whole Sterols Patterns of Various Oil Samples by GLC.

\begin{tabular}{|l|c|c|c|c|c|c|c|}
\hline \multirow{2}{*}{ Oil Sample } & \multirow{2}{*}{$\begin{array}{c}\text { Sterol } \\
\text { Content (\%) }\end{array}$} & \multicolumn{7}{|c|}{$\begin{array}{c}\text { Campe } \\
\text { sterol }\end{array}$} & $\begin{array}{c}\text { 5-stigma } \\
\text { sterol }\end{array}$ & $\begin{array}{c}\text { B-sito } \\
\text { sterol }\end{array}$ & $\begin{array}{c}\text { Isofuco } \\
\text { sterol }\end{array}$ & $\begin{array}{c}\text { 7-Stigma } \\
\text { Sterol }\end{array}$ & $\begin{array}{c}\text { 7-Avena } \\
\text { sterol }\end{array}$ \\
\cline { 3 - 8 } Wheat germ & 0.8 & 27.2 & 0.8 & 63.0 & 4.0 & 2.0 & 3.0 \\
\hline Grape seed & 0.7 & 11.4 & 10.5 & 75.6 & 1.0 & 1.5 & 0.5 \\
\hline Corn & 1.0 & 21.0 & 7.7 & 66.8 & 4.5 & - & - \\
\hline Sunflower & 0.9 & 9.0 & 12.5 & 60.5 & 3.0 & 11.0 & 4.0 \\
\hline Cottonseed & 0.6 & 10.0 & 2.4 & 80.0 & 7.6 & - & - \\
\hline
\end{tabular}


Table 4 Free and Acylated Sterylglycosides Pattern of Various Oil Samples by HPLC.

\begin{tabular}{|c|c|c|c|c|c|c|c|}
\hline \multirow[b]{2}{*}{ Oil Sample } & \multirow[b]{2}{*}{ SG Type } & \multirow{2}{*}{$\begin{array}{l}\text { Content } \\
\text { ppm }\end{array}$} & \multicolumn{5}{|c|}{ Free and acylated sterylglycosides Composition (\%) } \\
\hline & & & Avena-SG & Isofuco-SG & $\begin{array}{c}\text { Campe } \\
\text { stigma-SG }\end{array}$ & 7-stigma-SG & B-Sito-SG \\
\hline Wheat germ & $\begin{array}{l}\text { FSG } \\
\text { ASG } \\
\text { Total }\end{array}$ & $\begin{array}{r}460 \\
70 \\
530\end{array}$ & $\begin{array}{l}- \\
-\end{array}$ & $\begin{array}{l}3.5 \\
2.0\end{array}$ & $\begin{array}{l}20.1 \\
38.0\end{array}$ & $\begin{array}{l}- \\
-\end{array}$ & $\begin{array}{l}76.0 \\
60.0\end{array}$ \\
\hline Grape seed & $\begin{array}{l}\text { FSG } \\
\text { ASG } \\
\text { Total }\end{array}$ & $\begin{array}{r}150 \\
90 \\
240\end{array}$ & - & $\begin{array}{l}4.5 \\
4.5\end{array}$ & $\begin{array}{l}18.0 \\
20.0\end{array}$ & $\begin{array}{l}1.0 \\
1.5\end{array}$ & $\begin{array}{l}76.3 \\
74.0\end{array}$ \\
\hline Corn & $\begin{array}{l}\text { FSG } \\
\text { ASG } \\
\text { Total }\end{array}$ & $\begin{array}{r}105 \\
1533 \\
1658\end{array}$ & $\begin{array}{l}2.0 \\
2.5\end{array}$ & $\begin{array}{l}4.0 \\
4.0\end{array}$ & $\begin{array}{l}23.0 \\
26.2\end{array}$ & $\begin{array}{l}- \\
-\end{array}$ & $\begin{array}{l}71.0 \\
79.3\end{array}$ \\
\hline Sunflower & $\begin{array}{l}\text { FSG } \\
\text { ASG } \\
\text { Total }\end{array}$ & $\begin{array}{l}200 \\
174 \\
374\end{array}$ & $\begin{array}{l}3.0 \\
2.0\end{array}$ & $\begin{array}{l}7.5 \\
4.0\end{array}$ & $\begin{array}{l}13.0 \\
15.0\end{array}$ & $\begin{array}{l}1.5 \\
2.0\end{array}$ & $\begin{array}{l}75.0 \\
77.0\end{array}$ \\
\hline Cottonseed & $\begin{array}{l}\text { FSG } \\
\text { ASG } \\
\text { Total }\end{array}$ & $\begin{array}{r}230 \\
80 \\
310\end{array}$ & $\begin{array}{l}- \\
-\end{array}$ & $\begin{array}{l}5.0 \\
6.0\end{array}$ & $\begin{array}{l}9.0 \\
8.0\end{array}$ & $\begin{array}{l}- \\
-\end{array}$ & $\begin{array}{l}86.0 \\
86.0\end{array}$ \\
\hline
\end{tabular}

AN : Anthroylnitrile ; SG: sterylglycosides ; FSG : Free sterylglycoside and ASG : Acylated sterylglycoside

fuco, 7-stigma and 7-avenasterol at a level of 27.2, 0.8, 63.0, 4.0, 2.0 and $3.0 \%$ respectively for WGO and $11.4,10.5,75.6$, $1.0,1.5$ and $0.5 \%$ respectively for GSO. In comparison with the three conventional edible oils, it can be noticed that sunflower oil contained the same individual sterols present in WG and GS oils. On the other side, 7-stigma- and 7-avenasterol were not detected in corn and cottonseed oils. It can be noticed that WGO contained isofucosterol at a level of $4.0 \%$ in comparison to $4.5,3.0$ and $7.6 \%$ in case of corn, sunflower and cottonseed oils respectively. 7-Avenasterol constituted 3.0\%in WGO in comparison with $4.0 \%$ in sunflower oil.

\subsection{Sterylglycosides pattern}

The total sterylglycosides (SG's), free and acylated SG, amounted to $530 \mathrm{ppm}$ in WGO, whereas it was at a level of 240 ppm in GSO (Table 4). WGO SG was two fold the amount found in GSO. Concerning the three conventional oils, it was found that the total amount of SG in corn oil reached $1658 \mathrm{ppm}$ which was markedly higher than that of sunflower (374 ppm) and cottonseed oil (310 ppm). Dealing with free SG (FSG) of WGO, the pattern was lacking avena$\mathrm{SG}$ and 7 -stigma-SG.On the other hand $\beta$-sito-SG was present as a predominating compound, whereas, lower amount of isofuco-SG and reasonable amount of campe+stigma-SG were detected. On the other side, GSO was lacking only in avena-SG and the pattern was nearly the same as WGO with the exception of the presence of 7-stigm-SG at a level of $1.0 \%$. In comparison with the three conventional edible oils, it could be noticed that corn oil as well as cottonseed oil did not contain 7-stigm-SG; however cottonseed oil did not contain avena-SG. It is noteworthy that the sunflower profile of FSG contained the five SG components at a level of avena-SG (3.0\%), isofuco-SG (7.5\%), campe +stigma-SG (13.0\%), 7 -stigma-SG (1.5\%) and $\beta$-sito-SG (75.0\%). The individual distribution of ASG was the same as that of FSG in WG and GS oils as well as the three conventional edible oils.

\section{DISCUSSION}

In general, WG and GS oils contained essential fatty acids, namely, omega- 6 and omega- 3 which mean that these oils can be used as health and edible oils. In addition, the oils extracted from the two by-products contained reasonable amounts of oleic acid, a monounsaturated fatty acid. This monounsaturated fatty acid has great importance in terms of its nutritional implication and in improving the oxidative stability of oils ${ }^{21}$. It is known that low levels of linolenic acid are desired in edible oils, because high levels of this acid can produce unfavourable odour and taste in oil ${ }^{20)}$. Furthermore, the stability or shelf-life of oil rich in linolenic acid would be short because linolenic acid is easily oxidized ${ }^{30,31}$. So GSO, having a low quantity of this acid, can be advantageous in terms of human consumption and shelf-life of the oil. The reasonable percentage of unsaturation in WG and GS oils may play an important role in lowering high blood cholesterol and also in the treatment of atherosclerosis ${ }^{32}$. 
It seems that WGO is a rich source of alpha-tocopherol which is a high bioactive tocopherol component. Oils with high tocopherol content can be used in applications where high level of antioxidant protection is needed. On the other hand, among the tocopherols present in foods, alpha-tocopherol shows the highest vitamin $\mathrm{E}$ activity, thus making it the most important tocopherol for human health and biological activity ${ }^{33,34)}$. However, GSO was enriched with alpha- and gamma-tocotrienols which was unique among the other oil patterns under investigation. It is worthy to mention that there is a strong evidence of these tocotrienols for preventing narrowing (stenosis) of carotid $\operatorname{artery}^{29)}$.

Sterols play essential roles in the physiology of humans, also known to block cholesterol absorption sites in the human intestine thus helping to reduce cholesterol in humans and to provide important signals and metabolic communications eg. circadian rhythms, blood clotting.

The SG's have beneficial effect particularly it reduced the absorbability of cholesterol and fatty acids in the intestines, which resulted in reduced concentrations of plasma cholesterol and triacylglycerol ${ }^{35}$. Accordingly, WG and GS oils can be used as sources of SG.

\section{CONCLUSION}

Laboratory extracted oils from the two by-products, namely, wheat germ (WG) and grape seed (GS) contained predominating polyunsaturated fatty acids, particularly linoleic acid (omega-6) and linolenic acid (omega-3). These acids are essential for the human body physiological function since they can not be biosynthesized by the body. Accordingly, WG and GS oils, rich in linoleic and linolenic acids, may be considered as valuable sources of dietary oils. In addition, total tocopherols and tocotrienols amounted to $1300 \mathrm{ppm}$ in WGO and $380 \mathrm{ppm}$ in GSO. Alpha-tocopherol was predominating in WGO while, beta-tocopherol was present in reasonable amount (19.0\%) however, alphaand gamma-tocotrienols were found as main products in GSO. It is well known that, tocotrienols have been shown to reduce plasma cholesterol levels as well as other lipids and non-lipid related risk factors for cardiovascular diseases $(\mathrm{CVD})^{36}$.

With the development of analytical tools, bioactive sterylglycosides(SG's), comprising free and acylated compounds, were able to be determined. It worthy to mention that SG's suppress the absorption of cholesterol and fatty acids in the intestine i.e. they are considered as hypocholoesterolemic component ${ }^{35)}$.

The beneficial effects of WG and GS oils are due not only to their high polyunsaturates content, but also to their tocopherols and tocotrienols as natural antioxidant components. These components may serve as dietary sources for natural antioxidants scavenging free radicals and thus prevent the body from diseases and promote human health. Consequently, WG and GS oils are suitable as health oils and can be generally used for in pharmaceutical purposes since they are enriched in bioactive lipid components.

\section{ACKNOWLEDGMENTS}

The authors express their gratitude to Prof. Dr. Mohamed M. Hassan EL-Mallah and Prof. Dr. Safinaz M. EL-Shami of National Research Centre, Fats and Oils Dept. for their criticism and helpful discussion during the preparation of this work. In addition, thanks are given to Dr T. Murui (Nisshin Oil Mills Yokohama, Japan), for supplying standard sterylglycosides and facilities received in many ways.

\section{References}

1. Bass, E.J. Wheat flour milling, in Wheat: Chemistry and technology (Pomeranz, Y. ed.). Vol. 2 American Association of Cereal Chemists. St. Paul. pp.1-56 (1988).

2. Pomeranz, Y. Chemical composition of kernel structure, in Wheat: Chemistry and Technology (Pomeranz, Y. ed.). Vol. 1 American Association of Cereal Chemists. St. Paul. pp. 139-147 (1988).

3. Saito, M.; Yamanchi, Y. Isolation of tocopherols from wheat germ oil by recycle semi preparative supercritical fluid chromatography. J. Chromatogr. Sci. 505, 257-271 (1990).

4. EL-Mallah, M.; Murui, T. Local food industries by-products part 1-Grape seeds (Muskat), wheat germ and deodorization distillates of cottonseed oil. Specialities SOFW. J. 119 (1), 45-49 (1993).

5. Sonntag, N.O.V. Compositional and characteristics of individual fats and oils. in Bailey's industrial oil and fat products $4^{\text {th }}$ edn. (Swern, D. ed.). Vol. 4 John Wiley \& Sons. New York (1979).

6. Barns, J.P. Lipid composition of wheat germ and wheat germ oil. Fette, Seifen, Anstrichmitted 84 (7), 256-269 (2006).

7. Eisenmeger, M.; Dunford, T.N.; Eller, F.; Taylor, S.; Martinz, J. Pilot-scale supercritical carbon dioxide extraction and fractionation of wheat germ oils. J. Am. Oil Chem. Soc. 83 (10), 863-868 (2006).

8. Horrobin, D.; Manku, M. How do polyunsaturated fatty acids lower plasma cholesterol levels? Lipids 18, 558562 (1993).

9. Kahlon, T.S. Nutritional implications and uses of wheat and oat kernel oil. Cereal Foods World 43, 872-875 (1989).

10. Appelt, G. Nutritional value and stability of extruded 
Wheat germ product. Getreide Mehl Brot 40, 176-180 (1986).

11. Singh, L.; Rice, K.W. Method for producing wheat germ lipid product. U.S. patent 4,298,622 (1979).

12. Wang, T.; Johnson, A.L. Refining high-free fatty acid wheat germ oil. J. Am. Oil Chem. Soc. 78, 71-76 (2001).

13. Panfili, G.; Cinquanata, L.; Fratianni, A.; Cubadda, R. Extraction of wheat germ oil by supercritical $\mathrm{CO}_{2}$ : Oil and defatted cake characterization. J. Am. Oil Chem. Soc. 80(2), 157-161 (2003).

14. Dunford, N.T.; King, J.W. Supercritical fluid fractionation process for phytosterols ester enrichment in vegetable oils. U.S. Patent 6,677,469 (2004).

15. Barnes, J.P.; Taylor, W.P. The composition of acyl lipids and tocopherols in wheat germ oils from various sources. J. Sci. Food Agric. 31 (10), 997-1006 (2006).

16. Nerantizis, T.E.; Tataridis, P. Integrated enology-utilization of winery by-products into high added value products. E. J. Sci. Technol. (e-Jst) 1 (3), 179-189 (2006).

17. Christie, W.W. The Preparation of Volatile Derivatives of Lipids. in Lipid Analysis Chapter 4, pergamon press. pp. 85-102 (1973).

18. Beveridge, T.H.J.; Girad, B.; Kopp, T.; Drover, J.C.G. Yield and composition of grape seed oils extracted by supercritical carbon dioxide and petroleum ether: Varietal effects. J. Agric. Food Chem. 53, 1799-1804 (2005).

19. El-Shami, S.; EL-Mallah, M.H.; Mohamed, S.S. Studies on the lipid constituents of grape seeds recovered from pomace resulting from white grape processing. Grasas Y Aceites 43(3), 157-160 (1992).

20. Aparicio, R.; Roda, L.; Albi, M.A.; Gutierrez, F. Effect of various compounds on virgin olive oil stability measured by rancimat. J. Agric. Food Chem. 47, 4150-4155 (1999).

21. Baydar, G.N.; Ozkan, G.; Cetin, S.E. Characterization of grape seed and pomace oil extracts. Grasas Y Aceites 58(1), 29-33 (2007).

22. EL-Mallah M. Hassan; El-Shami S.; Hassanein, M.M. Studies on lipid profiles of vitis vinifera (grape) and lactuca scariola (oil lettuce) seed oils in comparison with those of soybean oil. J. Agric. Sci. Mansoura Univ. 28(4), 3179-3187 (2003).

23. Guerra, E.G.; Zuniga, M.E. Enzymatic treatment in the grape seed oil extraction, vitis vinifera, by cold preesing. Grasas Y Aceites, Sevilla 54(1), 53-57 (2003).

24. Official and Tentative Methods of the Am. Oil Chem. Soc. $3^{\text {rd }}$ edn. AOCS, Chicago, Illinois (1980).

25. EL-Mallah M. Hassan; Murui, T.; El-Shami, S. Detailed studies on seed oil of silicornia SOS-7 cultivated at the Egyptian border of red sea. Grasas Y Aceites 45(6), 385-389 (1994).

26. El-Shami S.; Hassanein, M.M.; Murui, T.; EL-Mallah, M.H. Studies of changes in patterns of fatty acids, sterols and tocopherols of oil during seed maturation part 1: Sunflower seeds. Grasas Y Aceites 45(4), 227231 (1994).

27. EL-Mallah M. Hassan; Murui, T.; El-Shami, S. New trends in determining the authenticity of corn oil. Grasas Y Aceites 50(1), 7 (1999).

28. Murui, T.; Wanaka, K.; Kuriyama, K. Determination of Sterylglycosides as their 1-Anthroylnitrile Derivatives. Biosci. Biotech. Biochem. 25, 614-617 (1993).

29. Papas, A.M. Tocotrienols: The new dimension of vitamin E. Lipid Technology Newsletter 81-85 (2000).

30. Hall, J.L.; Flower, T.J.; Roberts, R.M. Plant cell structure and metabolism. Longman Inc. New York (1981).

31. Mayes, P.A. Metabolism of lipid en fatty acids Harper's review of biochemistry. Medical Pub. Inc. California (1983).

32. Axtell, J.D. Breeding for improvement nutritional quality. in Plant Breeding (Frey, k.J. ed.). Vol.11 The Iowa State University Press. Iowa p.497 (1981).

33. Guthrie, N.; Kurowaska, E.M. Anticancer and cholesterol lowering activities of tocotrienols. in Nutraceuticals and Functional Foods (Wildman, R.E.C. ed.). CRC Press. Boca Raton. Florida. pp.269-280 (2001).

34. Abidi, S.L. Tocol-derived minor constituents in selected plant seed oils. Am. Oil Chem. Soc. 80(4) 327-333 (2003).

35. Murui, T.; Yoshikawa, M.; Takeuchi, H.; Fujii, S.; Mizobuchi, H.; Takeuchi, H. Effect of sterylglycosides from soybean on lipid indices in the plasma, liver and feces of rats. Biosci. Biotech. Biochem. 58(3), 494-497 (1994).

36. Theriault, A.; Chao, T.; Wang, Q.; Gapor, A.; Adeli, K. Tocotrienol: A review of its therapeutic potential. Clinical Biochemistry 32(5), 309-318 (1999). 